\title{
Application of a novel definitive screening design to decolorization of an azo dye on boron-doped diamond electrodes
}

\author{
M. Fidaleo ${ }^{1}$ R. Lavechia ${ }^{2}$ E. Petrucci ${ }^{2} \cdot$ A. Zuorro $^{2}$
}

Received: 20 June 2015/Revised: 29 October 2015/Accepted: 3 January 2016/Published online: 12 January 2016

(C) Islamic Azad University (IAU) 2016

\begin{abstract}
The electrochemical decolorization of the Reactive Violet 5 azo dye on a boron-doped diamond anode was used as a model process to test a novel definitive screening design (DSD). This method allows a dramatic reduction in the number of experiments needed to investigate those systems characterized by a large number of variables. In this study, the effect of nine quantitative parameters was investigated: initial dye concentration (60-120 mg L ${ }^{-1}$ ), current density (100-500 $\mathrm{A} \mathrm{m}^{-2}$ ), $\mathrm{NaCl}$ concentration $\quad(5-20 \mathrm{mM}), \quad \mathrm{Na}_{2} \mathrm{SO}_{4} \quad$ concentration (35-65 mM), pH (3-11), temperature $\left(20-45^{\circ} \mathrm{C}\right)$, interelectrode distance $(0.5-3.5 \mathrm{~cm})$, stirring rate (250-750 rpm) and electrolysis time (2-8 min). Analysis of DSD data showed that four out of the nine factors (initial dye concentration, current density, $\mathrm{pH}$ and electrolysis time) were statistically significant. These factors were retained for process characterization using a subsequent central composite design. Overall, the number of experiments was reduced from over 500 to only 41, thus confirming the validity of the proposed approach as a timesaving and efficient method.
\end{abstract}

Keywords Reactive Violet 5 - Boron-doped diamond electrode - Color removal · Definitive screening design . Central composite design

E. Petrucci

elisabetta.petrucci@uniroma1.it

1 Department for Innovation in Biological, Agro-Food, and Forest Systems, University of Tuscia, Via San Camillo de Lellis, 01100 Viterbo, Italy

2 Department of Chemical Engineering Materials and Environment, Sapienza University of Rome, Via Eudossiana 18, 00184 Rome, Italy

\section{Introduction}

In the analysis of problems affected by several factors with possible interactions, statistical screening methods are often adopted to select the parameters that actually affect the response variable and to eliminate the irrelevant ones. This is particularly useful at the beginning of an investigation, when little or no information is available for the system of interest. The significant factors are then investigated by applying designs of higher sensitivity.

In the most commonly used screening designs, each continuous factor is usually set at two levels. However, these methods are not able to provide information on possible curvature or on active pure-quadratic effects (Georgiou et al. 2014). The customarily addition of center runs to these designs to get a global assessment of curvature does not allow for separate estimation of the quadratic effects of each factor. To overcome this limitation, three-level methods should be used. Recently, a new class of three-level designs, the so-called definitive screening designs (DSDs), has been proposed by Jones and Nachtsheim (2011). DSDs allow for assessment of active effects, two-factor interactions and pure-quadratic effects in the presence of effect sparsity. Moreover, since each run, except for the center point, has one factor level at its zero level and all others at one of the extremes, the number of experimental tests required for $k$ factors is only $2 k+1$. For an odd number of factors, the authors suggest the inclusion of two extra runs to generate orthogonal designs for main effects. Compared to traditional screening methods, this allows a dramatic reduction in the number of experiments, thus enabling a significant saving in time and cost of materials.

Despite the apparent advantages of the DSD approach, very few experimental studies have yet been published on this subject (Xiao et al. 2012; Erler et al. 2013; Libbrecht 
et al. 2015). As a result, further validation studies are needed to confirm the usefulness of the method and highlight possible problems and limitations.

In this paper, we use a DSD approach to investigate the electrochemical decolorization of the azo dye Reactive Violet 5 (RV5) on a boron-doped diamond (BDD) anode. Azo dyes are the largest class of compounds used in the textile, paper, leather and plastic industries (Hunger 2003). RV5 is widely used in textile dyeing because of its brightness, ease of application and good fastness to washing. However, its poor fixation to the fibers results in the production of dye-contaminated wastewaters. If not properly treated, these effluents may have a negative impact on the environment and human health, due to the toxicity and potential carcinogenicity of the dye and its transformation products.

Several treatment methods, such as adsorption (Zuorro et al. 2013), microbial degradation (Jain et al. 2012; Fetyan et al. 2013), ozonation (Khare et al. 2007), $\mathrm{TiO}_{2}$ photocatalysis (Chung and Chen 2009) and anodic oxidation on manganese oxide-based electrodes (Sotgiu et al. 2014), have been investigated for the removal of RV5 from wastewater. Here, we explore the suitability of an electrochemical treatment based on the use of BDD thin-film electrodes to decolorize RV5. BDD electrodes are nonactive anodes capable of unselectively mineralizing organic compounds by means of the hydroxyl radicals physisorbed on their surface. Owing to its chemical inertness, wide potential window for hydrogen $(-1.25 \mathrm{~V}$ vs SHE) and oxygen evolution $(+2.3 \mathrm{~V}$ vs SHE), low capacitance and long-term response stability (Perret et al. 1999), the BDD anode is considered one of the most effective electrodes for practical applications. They include organic synthesis (Griesbach et al. 2010), detection of analytes (Zhou and Zhi 2009), inactivation of pathogenic microorganisms (Bensalah and Abdel-Wahab 2013; Mascia et al. 2013) and degradation of traditional (Oturan et al. 2012; Wang et al. 2013) or emerging contaminants (Brinzila et al. 2012; Steter et al. 2014). When azo dyes are treated by anodic oxidation on BDD, decolorization and mineralization occur simultaneously due to the non-selective reaction of the electrogenerated $\cdot \mathrm{OH}$ radicals that can attack either the $\mathrm{N}=\mathrm{N}$ double bond or the aromatic ring. In the presence of chlorides, BDD produces also a mixture of oxidants known as active chlorine with high selectivity toward the chromophore group, thus accelerating the color removal rate (Montanaro and Petrucci 2009). In this case, complete decolorization is achieved before mineralization occurs to a significant extent.

In our previous studies on the removal of azo dyes with BDD electrodes, we found that the removal efficiency was affected by a variety of factors including, among others, dye, chloride and supporting electrolyte concentrations, current density, $\mathrm{pH}$, temperature, stirring rate and time (Montanaro and Petrucci 2009; Zuorro et al. 2014; Petrucci et al. 2015a, b). This electrochemical treatment therefore represents an ideal test bench for the experimental validation of methods based on DSD strategies.

\section{Materials and methods}

\section{Chemicals and materials}

RV5 of technical grade $\left(\mathrm{C}_{20} \mathrm{H}_{16} \mathrm{~N}_{3} \mathrm{Na}_{3} \mathrm{O}_{15} \mathrm{~S}_{4}\right.$, MW $735.59 \mathrm{~g} \mathrm{~mol}^{-1}$, color index number 18097) was provided by Gammacolor Srl (Seveso, Italy) and used as received.

Sodium hydroxide (NaOH, CAS No. 1310-73-2) and sodium sulfate $\left(\mathrm{Na}_{2} \mathrm{SO}_{4}\right.$, CAS No. 7757-82-6) were purchased from Sigma-Aldrich (Milano, Italy). Sodium chloride ( NaCl, CAS No. 7647-14-5) and sulfuric acid $\left(\mathrm{H}_{2} \mathrm{SO}_{4}\right.$, CAS 7664-93-9) were from Carlo Erba Reagenti (Milano, Italy).

The dyestuff solutions were prepared by dissolving appropriate amounts of $\mathrm{RV} 5, \mathrm{NaCl}$ and $\mathrm{Na}_{2} \mathrm{SO}_{4}$, the supporting electrolyte, in doubly deionized water, which was obtained using a Sartorius Arium 611 D1 purification system (total organic content $<0.1 \mathrm{ppm}$ and conductivity $<0.05 \mathrm{mS} \mathrm{cm}^{-1}$ ).

The $\mathrm{pH}$ was adjusted to the desired value by addition of small amounts of $96 \% \mathrm{H}_{2} \mathrm{SO}_{4}$ and $0.1 \mathrm{M} \mathrm{NaOH}$.

\section{Electrochemical experiments}

The experiments were conducted in an undivided glass reactor of cylindrical shape with a volume of about $250 \mathrm{~mL}$. The reactor was thermostated and vigorously stirred with a magnetic bar. A BDD thin-film electrode supplied by Adamant Technologies (Neuchatel, Switzerland) was used as the anode, while the cathode was a platinum disk. The electrodes had a surface area of $5 \mathrm{~cm}^{2}$ and were placed vertically at the desired inter-electrode distance. Electrolyses were carried out on $100-\mathrm{mL}$ dye solutions under galvanostatic conditions using an AMEL 2051 potentiostat/galvanostat. At selected times, aliquots of the solution were withdrawn and analyzed for color.

\section{Analytical methods}

The solution $\mathrm{pH}$ and conductivity were measured using a Crison GLP 421 pH-meter and a Hanna Instrument HI87314 electrical conductivity meter, respectively.

Color removal was monitored by measuring the absorbance decrease at $560 \mathrm{~nm}$, where the absorption spectrum of RV5 displays a maximum. Measurements were taken with a double-beam UV/Vis spectrophotometer (PG Instruments T80+) using glass cells of 1-cm path length. 


\section{Experimental design}

The DSD proposed by Jones and Nachtsheim (2011) was adopted to investigate the effects of nine continuous factors $(k=9)$ that were identified, in preliminary runs, as potentially important for the electrolytic process. They were: temperature $(T), \mathrm{pH}$, dye $\left(c_{D}\right), \mathrm{NaCl}\left(c_{C}\right)$ and sulfate concentration $\left(c_{S}\right)$, agitation rate $(A)$, current density $(J)$, electrolysis time $(t)$ and inter-electrode distance $(D)$. For each factor, natural values corresponding to the coded levels of $-1,0$ and +1 were selected to cover a range of values of practical interest and on the basis of the results of preliminary experiments conducted to assess their individual effect on the decolorization efficiency. In particular, chloride concentrations were evinced by a previous work (Montanaro and Petrucci 2009), while sulfate values lie within the range usually adopted for a supporting electrolyte. The electrolysis time was kept as low as possible (2-8 $\mathrm{min}$ ) to avoid masking the effects of the other factors. In fact, in preliminary tests (data not reported here) conducted with longer electrolysis time (4-12 $\mathrm{min})$, the extent of color decay was so high that in 18 out of 23 runs a decolorization efficiency higher than $60 \%$ was achieved. In addition, among them, 9 runs exhibited a decolorization efficiency higher than $95 \%$, thus complicating the interpretation of results.

Coded values $\left(x_{i}\right)$ were obtained from the actual ones $\left(X_{i}\right)$ using the following transformations:

$x_{i}=\frac{X_{i}-X_{i, 0}}{\Delta X_{i}}$

where $X_{i, O}$ is the actual value of the $i$-th factor at the centerpoint level and $\Delta X_{i}$ is the step change value for that factor.

Coded and actual values of the design factors are reported in Table 1.

Table 1 Factors with coded and natural levels for the DSD

\begin{tabular}{|c|c|c|c|c|c|c|}
\hline \multicolumn{3}{|c|}{ Factor } & \multicolumn{3}{|c|}{ Factor level } & \multirow[t]{2}{*}{ Unit } \\
\hline & & & -1 & 0 & +1 & \\
\hline 1 & $T$ & Temperature & 20 & 35 & 50 & ${ }^{\circ} \mathrm{C}$ \\
\hline 2 & $p H$ & $\mathrm{pH}$ & 5 & 8 & 11 & - \\
\hline 3 & $c_{D}$ & Dye concentration & 60 & 90 & 120 & $\mathrm{mg} \mathrm{L}^{-1}$ \\
\hline 4 & $c_{C}$ & $\begin{array}{l}\text { Chloride } \\
\text { concentration }\end{array}$ & 5 & 12.5 & 20 & $\mathrm{mM}$ \\
\hline 5 & $c_{S}$ & Sulfate concentration & 35 & 50 & 65 & $\mathrm{mM}$ \\
\hline 6 & $A$ & Agitation rate & 250 & 500 & 750 & $\mathrm{rpm}$ \\
\hline 7 & $J$ & $\begin{array}{l}\text { Electric current } \\
\text { density }\end{array}$ & 100 & 300 & 500 & $\mathrm{~A} \mathrm{~m}^{-2}$ \\
\hline 8 & $t$ & Electrolysis time & 2 & 5 & 8 & $\min$ \\
\hline 9 & $D$ & $\begin{array}{l}\text { Inter-electrode } \\
\text { distance }\end{array}$ & 0.5 & 2 & 3.5 & $\mathrm{~cm}$ \\
\hline
\end{tabular}

Table 2 Experimental design layout and observed response $(y)$ for the DSD

\begin{tabular}{lrrrrrrrrrr}
\hline Run & \multicolumn{1}{c}{ Coded factor level } & & & & & & Response \\
\cline { 2 - 8 } & $x_{1}$ & $x_{2}$ & $x_{3}$ & $x_{4}$ & $x_{5}$ & $x_{6}$ & $x_{7}$ & $x_{8}$ & $x_{9}$ & $y(\%)$ \\
\hline 1 & 0 & 1 & 1 & 1 & 1 & 1 & 1 & 1 & 1 & 96.3 \\
2 & 0 & -1 & -1 & -1 & -1 & -1 & -1 & -1 & -1 & 3.6 \\
3 & 1 & 0 & -1 & -1 & -1 & -1 & 1 & 1 & 1 & 99.1 \\
4 & -1 & 0 & 1 & 1 & 1 & 1 & -1 & -1 & -1 & 7.4 \\
5 & 1 & -1 & 0 & -1 & 1 & 1 & -1 & -1 & 1 & 6.4 \\
6 & -1 & 1 & 0 & 1 & -1 & -1 & 1 & 1 & -1 & 96.9 \\
7 & 1 & -1 & -1 & 0 & 1 & 1 & 1 & 1 & -1 & 98.6 \\
8 & -1 & 1 & 1 & 0 & -1 & -1 & -1 & -1 & 1 & 14.2 \\
9 & 1 & -1 & 1 & 1 & 0 & -1 & -1 & 1 & -1 & 40.8 \\
10 & -1 & 1 & -1 & -1 & 0 & 1 & 1 & -1 & 1 & 75.2 \\
11 & 1 & -1 & 1 & 1 & -1 & 0 & 1 & -1 & 1 & 60.3 \\
12 & -1 & 1 & -1 & -1 & 1 & 0 & -1 & 1 & -1 & 59.9 \\
13 & 1 & 1 & -1 & 1 & -1 & 1 & 0 & -1 & -1 & 93.8 \\
14 & -1 & -1 & 1 & -1 & 1 & -1 & 0 & 1 & 1 & 84.1 \\
15 & 1 & 1 & -1 & 1 & 1 & -1 & -1 & 0 & 1 & 75.7 \\
16 & -1 & -1 & 1 & -1 & -1 & 1 & 1 & 0 & -1 & 46.4 \\
17 & 1 & 1 & 1 & -1 & -1 & 1 & -1 & 1 & 0 & 50.0 \\
18 & -1 & -1 & -1 & 1 & 1 & -1 & 1 & -1 & 0 & 62.1 \\
19 & 1 & 1 & 1 & -1 & 1 & -1 & 1 & -1 & -1 & 33.5 \\
20 & -1 & -1 & -1 & 1 & -1 & 1 & -1 & 1 & 1 & 33.1 \\
21 & 0 & 0 & 0 & 0 & 0 & 0 & 0 & 0 & 0 & 40.6 \\
\hline
\end{tabular}

The percentage color removal at the preset time $(t)$, defined as:

$y=100 \frac{A_{0}-A_{t}}{A_{0}}$

was the response variable. In the above equation, $A_{0}$ and $A_{t}$ are the absorbances of the dye solution at $t=0$ and $t$, respectively.

Overall, the experimental design consisted of $2 k+3=21$ runs, which were conducted randomly to minimize the effects of uncontrolled factors. The design layout and the observed color removal efficiencies are shown in Table 2.

The design and analysis of experiments were performed with the statistical software JMP ${ }^{\circledR}$, release 10 (SAS Institute, Cary, NC, USA).

\section{Results and discussion}

As can be seen in Fig. 1, the UV-Vis spectrum of RV5 exhibits an intense absorption peak in the visible region $(\lambda=560 \mathrm{~nm})$ which is due to the azo chromophore and is responsible for the violet color of the dye. The broad bands in the UV region arise from the $\pi \rightarrow \pi^{*}$ transitions of the aromatic structures: In particular, the sharp peak at $325 \mathrm{~nm}$ can be attributed to the naphthyl rings and that at lower wavelength to 


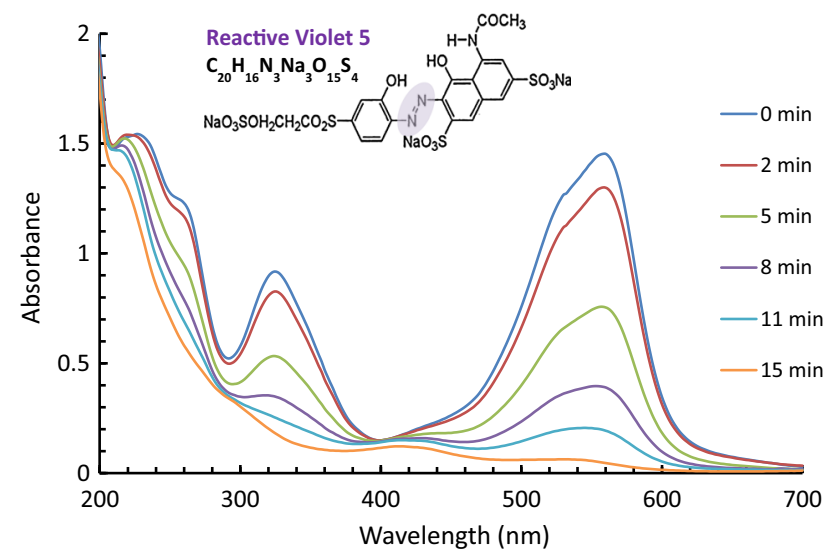

Fig. 1 UV-Vis spectra of RV5 at different electrolysis times $\left(T=35{ }^{\circ} \mathrm{C} ; \mathrm{pH}=8 ; c_{D}=90 \mathrm{mg} \mathrm{L}^{-1} ; c_{C}=12.5 \mathrm{mM} ; c_{S}=50\right.$ $\mathrm{mM} ; A=500 \mathrm{rpm} ; J=300 \mathrm{~A} \mathrm{~m}^{-2} ; D=2 \mathrm{~cm}$ )

the phenyl substituents (Bheemaraddi et al. 2014). The bathochromic shift of the bands toward longer wavelengths is due to the presence of functional groups in the aromatic rings.

During the electrochemical treatment, the absorption peak at $560 \mathrm{~nm}$ decreased markedly and the absorbance decay at this wavelength was used to assess the extent of decolorization of the dye solution. Preliminary experiments (not reported here) were performed to gain information on the kinetics of dye decolorization, identify the factors to be considered and define their range of values.

Analysis of DSD data was carried out by a two-step procedure involving a forward stepwise regression followed by an all-subsets regression using the corrected Akaike information criterion (AICc) and the Bayesian information criterion (BIC) to determine the model with the best prediction capability. In the first step, the forward stepwise regression method with a full quadratic regression model (containing main, two-way interaction and quadratic terms) was used to evaluate the total number of effects that were likely to be active. In the second step, the all-subsets regression analysis was used to examine all possible models of sizes up to and including that of the largest model determined from the forward stepwise regression. Only hierarchical models were considered for model selection.

The forward selection procedure indicated that a model containing $k=6$ terms was sufficient. It is worth noting that the same result, and the same model, could be obtained by using the forward selection procedure with a $p$ value to enter terms in the model of 0.05. All-subsets regression based on AICc and BIC values with a maximum model size of $k=6$ terms resulted in the following model equation:

$y=b_{0}+b_{2} x_{2}+b_{3} x_{3}+b_{7} x_{7}+b_{8} x_{8}+b_{23} x_{2} x_{3}$

where $x_{i}$ are the coded factors and $y$ is the response variable. Table 3 reports the estimates of the model coefficients together with the associated statistics.
Table 3 Estimates of the regression coefficients of the model described by Eq. (3) together with their corresponding standard errors (SE), $t$ values $(t)$ and $p$ values $(p)$

\begin{tabular}{llrrrr}
\hline Coefficient & Term & Estimate & SE & $t$ value & $p$ value \\
\hline$b_{0}$ & Intercept & 56.1 & 3.4 & 16.4 & $<0.0001$ \\
$b_{2}$ & $\mathrm{pH}$ & 8.9 & 3.7 & 2.4 & 0.0290 \\
$b_{3}$ & $c_{D}$ & -9.3 & 3.7 & -2.5 & 0.0229 \\
$b_{7}$ & $J$ & 21.0 & 3.7 & 5.7 & $<0.0001$ \\
$b_{8}$ & $t$ & 16.8 & 3.7 & 4.6 & 0.0004 \\
$b_{23}$ & $\mathrm{pH} \times c_{D}$ & -9.0 & 3.9 & -2.3 & 0.0353 \\
\hline
\end{tabular}

The coefficient of determination $\left(R^{2}\right)$ was equal to $82 \%$, the root-mean-square error (RMSE) was $15.6 \%$, AICc was 190.64, and BIC was 189.34. From Table 3, it can be seen that current density and electrolysis time were the most influential factors and both had a positive effect on the decolorization efficiency. Initial dye concentration and $\mathrm{pH}$ were involved in a significant two-way interaction. Dye concentration had a negative effect on $y$ at high $\mathrm{pH}$, while it did not affect the decolorization efficiency at low $\mathrm{pH}$. At the high level of dye concentration, the $\mathrm{pH}$ did not affect $y$, while at the low level, the $\mathrm{pH}$ exhibited a positive main effect.

All factors that were not included in the model (temperature, chloride and sulfate concentrations, agitation rate and inter-electrode distance) were screened out. For some of them, it is not difficult to explain the absence or the small significance of their effect on decolorization. In practical applications, the inter-electrode distance is usually kept small to reduce ohmic drops and hence energy consumption, as well as to enhance mass transfer. In fact, fluid dynamics and mass transport play a major role in the process kinetics (Scialdone et al. 2011) and become particularly relevant in electrocoagulation processes (Nandi and Patel 2014) or when the solution presents a relatively low conductivity. The fact that our experiments were unaffected by this factor and the agitation rate confirmed that, under the conditions adopted, the process was not under mass transfer control and that there was no need to enhance the mobility of the electrogenerated species.

As reported in previous studies, the electrolysis on BDD electrodes of solutions containing sulfates can generate sulfate radicals [Eq. (4)]. This species not only has a high oxidizing power (2.6 V vs SHE) but also can mediate the production of other oxidants such as peroxodisulfate [Eq. (5)] (Cañizares et al. 2009), chlorine radical [Eq. (6)] (Anipsitakis et al. 2006) and hydroxyl radicals [Eq. (7)] (Deng and Ezyske 2011; Zuorro and Lavecchia 2014), thus enhancing the degradation efficiency.

$\mathrm{SO}_{4}^{2-}+\mathrm{BDD}(\cdot \mathrm{OH}) \rightarrow \mathrm{BDD}+\mathrm{SO}_{4}^{-\cdot}+\mathrm{OH}^{-}$ 
$2 \mathrm{SO}_{4}^{-\cdot} \rightarrow \mathrm{S}_{2} \mathrm{O}_{8}^{2-}$

$\mathrm{SO}_{4}^{-\cdot}+2 \mathrm{Cl}^{-} \rightarrow \mathrm{Cl}_{2}^{-\cdot}+\mathrm{SO}_{4}^{2-}$

$\mathrm{SO}_{4}^{-\cdot}+\mathrm{H}_{2} \mathrm{O} \rightarrow \cdot \mathrm{OH}+\mathrm{HSO}_{4}^{-}$

However, the electrogeneration of sulfate radicals occurs more likely under high current density and in the presence of considerable amounts of sulfate (Michaud et al. 2000). In our case, due to the low concentration of sulfates and the relatively narrow range of current density, sulfate radical formation, though not excludable, can be expected to be negligible and not relevant to the oxidation process.

Temperature is generally detrimental to color removal since it negatively affects the solubility of gaseous chlorine and therefore the amount of electrogenerated active chlorine that is responsible for the oxidative attack to the chromophores. Moreover, an increase in temperature can shift the equilibrium of active chlorine species toward hypochlorite, with a further reduction in oxidizing power. Nonetheless, controversial data can be found in the literature suggesting that the presence (Zuorro et al. 2014) or the

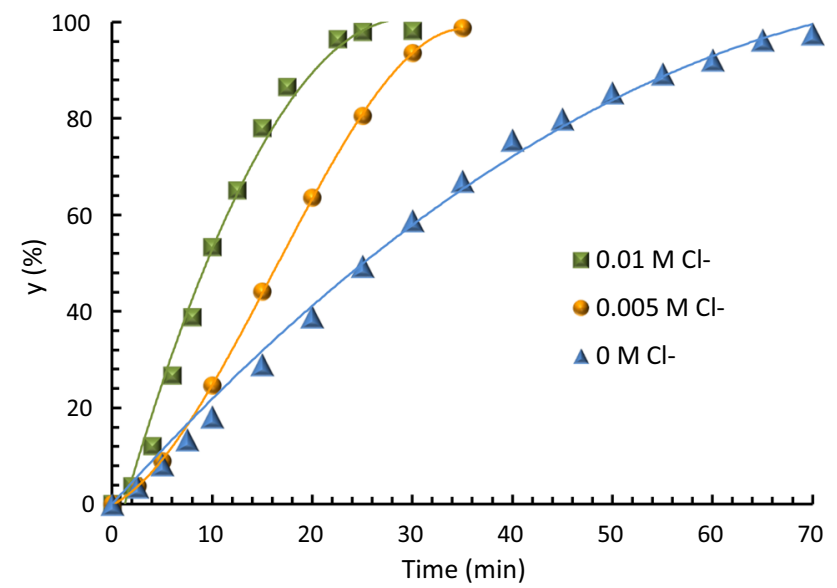

Fig. 2 Effect of chloride on the time course of dye decolorization $\left(T=25{ }^{\circ} \mathrm{C} ; \mathrm{pH}=7 ; c_{D}=90 \mathrm{mg} \mathrm{L}^{-1} ; c_{S}=50 \mathrm{mM} ; A=500 \mathrm{rpm}\right.$; $\left.J=300 \mathrm{~A} \mathrm{~m}^{-2} ; D=2 \mathrm{~cm}\right)$ absence (Montanaro and Petrucci 2009; Aquino et al. 2013) of an effect is strictly related to the dye chemical structure.

An unexpected result arising from the screening design is that color removal was not significantly dependent on chloride concentration. This apparently contradicts previous studies, where an enhancement of decolorization due to the chloride-mediated electrooxidation of the chromophore was always observed. To provide further insight into this issue, some prolonged electrolyses were carried out, in the absence or presence of chloride, under the conditions of the central point. The results obtained show that, contrary to other dyes, also in the absence of chloride RV5 undergoes rapid degradation and that complete decolorization is achieved in only $70 \mathrm{~min}$ (Fig. 2). The addition of $0.005 \mathrm{M}$ chloride enhanced the chromophore attack, thus reducing the time of decolorization, although far less than what would be expected. Increasing the chloride addition to $0.01 \mathrm{M}$ resulted in a slight improvement in the decolorization efficiency. Since the analysis of the commercial dye product used showed the presence of trace chloride, the observed behavior could be attributed to the impurity of the product. However, the complex chemical structure of RV5 could also contribute to the above-mentioned peculiarity. Further studies are needed for an in-depth understanding of the mechanisms involved.

To check for the accuracy and the predictive capability of the model described by Eq. (3), six additional experiments were performed. The experimental conditions and the observed $\left(y_{\text {obs }}\right)$ and predicted $\left(y_{\text {pred }}\right)$ responses are reported in Table 4 . We note that all the predicted values were included in the $95 \%$ prediction intervals for single observations. Moreover, by comparing the main effect of $\mathrm{pH}$ at the low ( $y$ for run 2, minus $y$ for run 1) and high level of $c_{D}$ ( $y$ for run 4, minus $y$ for run 3 ), the presence of an interaction between $\mathrm{pH}$ and $c_{D}$ can be easily seen. The combined large main effect of electric current density and electrolysis time is accurately evaluated by comparing the responses for run 5 and 6 . Thus, even if with the relatively low precision that is inherent in screening experiments, the
Table 4 Experimental conditions and results of validation experiments

\begin{tabular}{|c|c|c|c|c|c|c|c|}
\hline \multirow[t]{2}{*}{ Run } & \multicolumn{4}{|c|}{ Factor level } & \multicolumn{3}{|c|}{ Response } \\
\hline & $\mathrm{pH}$ & $c_{D}\left(\mathrm{mg} \mathrm{L}^{-1}\right)$ & $J\left(\mathrm{~A} \mathrm{~m}^{-2}\right)$ & $t(\min )$ & $y_{\mathrm{obs}}(\%)$ & $y_{\text {pred }}(\%)$ & PI $(\%)$ \\
\hline 1 & 5 & 60 & 300 & 5 & 71.3 & 47.5 & 10.7 to 84.3 \\
\hline 2 & 11 & 60 & 300 & 5 & 85.1 & 83.4 & 46.5 to 120.2 \\
\hline 3 & 5 & 120 & 300 & 5 & 57.6 & 46.9 & 10.1 to 83.7 \\
\hline 4 & 11 & 120 & 300 & 5 & 51.2 & 46.6 & 9.8 to 83.4 \\
\hline 5 & 11 & 120 & 100 & 2 & 11.1 & 8.8 & -29.6 to 47.3 \\
\hline 6 & 11 & 120 & 500 & 8 & 91.5 & 84.4 & 45.9 to 122.8 \\
\hline
\end{tabular}

$y_{\mathrm{obs}}$ and $y_{\text {pred }}$ are the observed and predicted responses, while PI denotes the corresponding prediction intervals

$T$ was set at the -1 level, $c_{C}$ at the +1 level and the remaining factors $\left(c_{S}, A\right.$ and $\left.D\right)$ at their center-point levels 
Table 5 Factors with coded and natural levels for the CCD

\begin{tabular}{|c|c|c|c|c|c|c|c|c|}
\hline \multicolumn{3}{|c|}{ Factor } & \multicolumn{5}{|c|}{ Factor level } & \multirow[t]{2}{*}{ Unit } \\
\hline & & & -1.68 & -1 & 0 & +1 & +1.68 & \\
\hline 1 & $c_{D}$ & Dye concentration & 39.55 & 60 & 90 & 120 & 140.45 & $\mathrm{mg} \mathrm{L}^{-1}$ \\
\hline 2 & $J$ & $\begin{array}{l}\text { Electric current } \\
\text { density }\end{array}$ & 65.91 & 100 & 150 & 200 & 234.09 & $\mathrm{~A} \mathrm{~m}^{-2}$ \\
\hline 3 & $t$ & Electrolysis time & 0.45 & 2.5 & 5.5 & 8.5 & 10.54 & $\min$ \\
\hline
\end{tabular}

Table 6 Factors, coded levels, observed $\left(y_{\text {obs }}\right)$ and calculated $\left(y_{\text {pred }}\right)$ conversions for the CCD

\begin{tabular}{|c|c|c|c|c|c|}
\hline \multirow[t]{2}{*}{ Run } & \multicolumn{3}{|c|}{ Factor level } & \multicolumn{2}{|l|}{ Response } \\
\hline & $x_{1}$ & $x_{2}$ & $x_{3}$ & $y_{\text {obs }}(\%)$ & $y_{\text {calc }}(\%)$ \\
\hline 1 & -1 & -1 & -1 & 26.7 & 33.4 \\
\hline 2 & +1 & -1 & -1 & 13.9 & 10.3 \\
\hline 3 & -1 & +1 & -1 & 33.0 & 45.6 \\
\hline 4 & +1 & +1 & -1 & 19.0 & 22.4 \\
\hline 5 & -1 & -1 & +1 & 87.9 & 84.1 \\
\hline 6 & +1 & -1 & +1 & 60.0 & 60.1 \\
\hline 7 & -1 & +1 & +1 & 94.0 & 96.2 \\
\hline 8 & +1 & +1 & +1 & 67.3 & 73.0 \\
\hline 9 & -1.68 & 0 & 0 & 85.6 & 78.6 \\
\hline 10 & +1.68 & 0 & 0 & 40.0 & 39.7 \\
\hline 11 & 0 & -1.68 & 0 & 43.8 & 50.0 \\
\hline 12 & 0 & +1.68 & 0 & 78.2 & 69.4 \\
\hline 13 & 0 & 0 & -1.68 & 8.2 & -0.2 \\
\hline 14 & 0 & 0 & +1.68 & 85.0 & 85.0 \\
\hline 15 & 0 & 0 & 0 & 53.3 & 59.2 \\
\hline 16 & 0 & 0 & 0 & 62.7 & 59.2 \\
\hline 17 & 0 & 0 & 0 & 60.4 & 59.2 \\
\hline 18 & 0 & 0 & 0 & 66.1 & 59.2 \\
\hline 19 & 0 & 0 & 0 & 56.6 & 59.2 \\
\hline 20 & 0 & 0 & 0 & 60.6 & 59.2 \\
\hline
\end{tabular}

$x_{1}, x_{2}$ and $x_{3}$ refer to $c_{D}, J$ and $t$ variables, respectively

sign of the main effects and their interactions is correctly predicted.

With the aim of maximizing dye conversion, the $\mathrm{pH}$ was set at its high level $(\mathrm{pH}=11)$, while dye concentration, electric current density and electrolysis time were retained as factors for the characterization of the system through a central composite design (CCD). Table 5 reports the new levels of the above-mentioned three factors in coded and natural form. For the follow-up experimentation, the temperature was set at the -1 level $\left(T=20^{\circ} \mathrm{C}\right)$, chloride concentration at the +1 level $\left(c_{C}=20 \mathrm{mM}\right)$, sulfate concentration, agitation rate and inter-electrode distance at their center levels $\left(c_{S}=50 \mathrm{mM}, A=500 \mathrm{rpm}\right.$ and $D=2 \mathrm{~cm}$, respectively). Finally, electric current density $(J)$ and electrolysis time $(t)$ were rescaled based on the results of the DSD. In particular, Eq. (2) was used through
Table 7 Estimates of the regression coefficients of the model described by Eq. (8) together with their corresponding standard errors (SE), $t$ statistics $(t)$ and $p$ values $(p)$

\begin{tabular}{llrrrc}
\hline Coefficient & Term & Estimate & SE & $t$ value & $p$ value \\
\hline$b_{0}^{\prime}$ & Intercept & 59.2 & 1.8 & 32.5 & $<0.0001$ \\
$b_{1}^{\prime}$ & $c_{D}$ & -11.6 & 1.7 & -6.7 & $<0.0001$ \\
$b_{2}^{\prime}$ & $J$ & 6.1 & 1.7 & 3.5 & 0.003 \\
$b_{3}^{\prime}$ & $t$ & 25.3 & 1.7 & 14.7 & $<0.0001$ \\
$b_{33}^{\prime}$ & $t^{2}$ & -5.9 & 1.7 & -3.6 & 0.003 \\
\hline
\end{tabular}

All coefficients are statistically significant at the $95 \%$ confidence level

JMP profiler to reduce the above-mentioned intervals so that, under the factor settings of the $\mathrm{CCD}$, the roughly predicted conversions were lower than $100 \%$, in order to reduce the probability of obtaining 'burned' runs (that is, runs that do not give information on the rate of the process because dye conversion is complete). This led to (100, $\left.200 \mathrm{~A} \mathrm{~m}^{-2}\right)$ and $(2.5,8.5 \mathrm{~min})$ as $(-1,+1)$ intervals for $J$ and $t$, respectively. Response data collected for the CCD are reported in Table 6 . They were fitted by a reduced second-order polynomial model:

$y=b_{0}^{\prime}+b_{1}^{\prime} x_{1}+b_{2}^{\prime} x_{2}+b_{3}^{\prime} x_{3}+b_{33}^{\prime} x_{3}^{2}$

The estimated coefficients and the associated statistics are summarized in Table 7. The analysis of residuals did not reveal any departure from normality and constant variance assumptions. Furthermore, the reduced polynomial described accurately the mean structure of the system, since there was no lack of fit at the $95 \%$ confidence level ( $p$ value of $15.9 \%)$. The RMSE, as obtained by pooling the pure error term and the lack of fit term, was $6.4 \%$, while $R^{2}$ and adjusted $R^{2}$ were 0.95 and 0.94 , respectively.

According to Eq. (8), in the restricted design space of the CCD, $y$ can be described by a simple additive model without interaction terms. This means that the effect produced by each variable is independent from the settings of the other variables. While $c_{D}$ and $J$ acted linearly on the extent of color removal, $t$ affected the response variable through a linear and a quadratic term, which makes physical sense since, except for zero-order reactions, conversions are not linear functions of time. Figure 3 shows the surface and contour plots of $y$ as a function of the three 
Fig. 3 Response surface and contour plots obtained from Eq. (8) showing the effect of RV5 concentration $\left(c_{D}\right)$, electrolysis time $(t)$ and electric current density $(J)$ on the decolorization efficiency $(y)$. For each plot, one of the three factors of the CCD was held at its central level
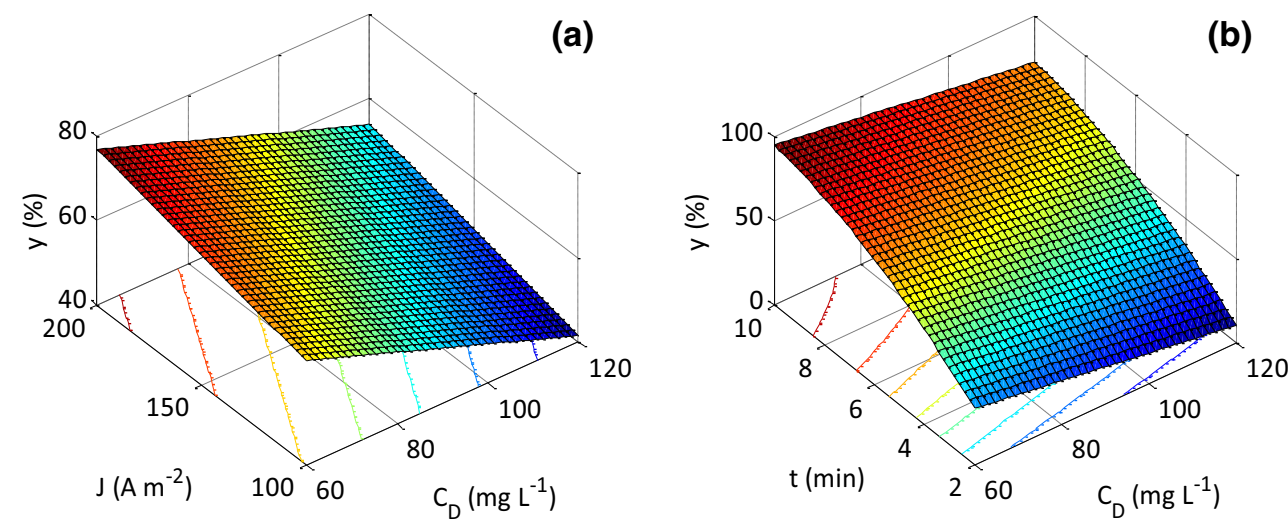

(b)

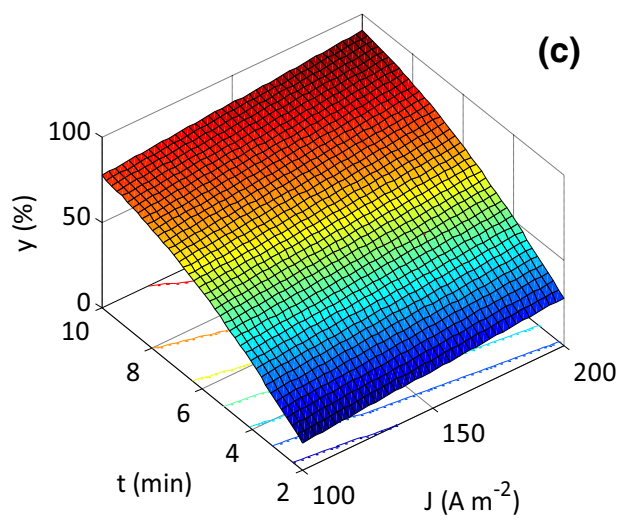

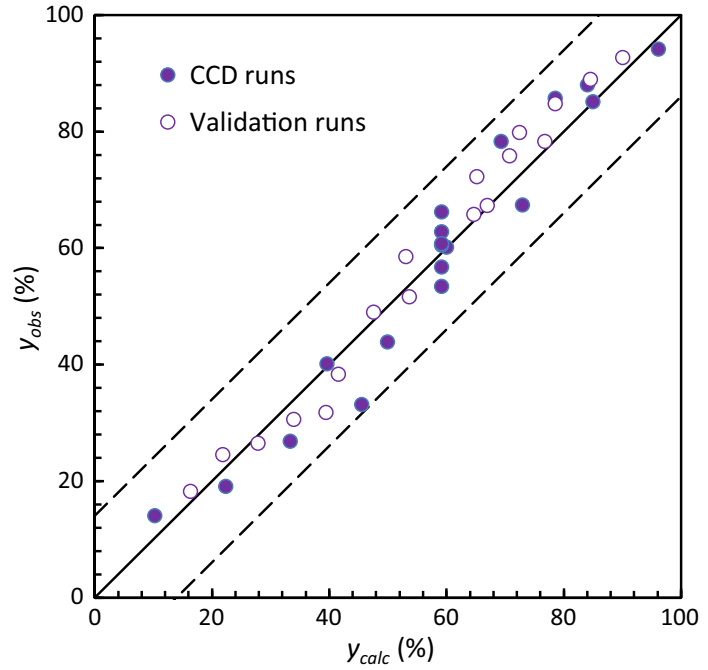

Fig. 4 Comparison between experimental $\left(y_{\exp }\right)$ and calculated $\left(y_{\text {calc }}\right)$ color removal efficiencies obtained by using Eq. (8) with the regression coefficients reported in Table 7 . The dashed lines delimit the $95 \%$ prediction intervals for future observations

factors as obtained from Eq. (8). We see that current density and electrolysis time had a positive effect on $y$, while dye concentration exerted a negative effect. Furthermore, the response surface did not present a stationary point inside the experimental region (maximum, minimum or saddle point). The maximum conversion predicted by the model corresponded to the vertex of the cuboidal experimental region $(-1,+1,+1)$ for which the experimental and predicted conversions were 94.0 and $96.2 \%$ (Table 6, run 7), respectively, thus in good agreement.

To assess the predictive capability of the model, several validation experiments were carried out in the region of experimentation delimitated by the factorial points $\left(x_{i}\right.$ varying between -1 and +1$)$. By using the reduced regression model described by Eq. (8) together with the parameter estimates reported in Table 7, it was possible to calculate the predicted values of $y$ as well as the $95 \%$ prediction intervals for future observations. As shown in Fig. 4, all the single observations ( $y_{\text {obs }}$ ) were in good agreement with the predicted values $\left(y_{\text {pred }}\right)$ and fell into the $95 \%$ prediction intervals, thus validating the model developed. Equation (8) can therefore be used to predict the decolorization efficiency of a dye-containing wastewater, once the concentration of the dye in the effluent to treat is known.

\section{Conclusion}

The results obtained in this study indicate that a DSD approach can be effectively used to identify the factors that most affect the electrochemical decolorization of an azo 
dye and that a subsequent experimentation using a CCD can lead to a significant improvement in the model. Application of this procedure to RV5 decolorization allowed reducing the total number of runs from the over 500 that would have been required using the traditional screening/RSM approach to only 41 (21 for DSD +20 for CCD).

Although further validation of the proposed DSD strategy is needed, our findings strongly support its use as a powerful means for designing experiments, especially when the number of factors to be considered is large and little prior knowledge is available on their effect on process response.

Acknowledgments The authors gratefully thank Gammacolor Srl (Seveso, Italy) for providing the azo dye RV5.

\section{References}

Anipsitakis GP, Dionysiou DD, Gonzalez MA (2006) Cobaltmediated activation of peroxymonosulfate and sulfate radical attack on phenolic compounds. Implications of chloride ions. Environ Sci Technol 40:1000-1007

Aquino JM, Rocha-Filho RC, Rodrigo MA, Sáez C, Cañizares P (2013) Electrochemical degradation of the Reactive Red 141 dye using a boron-doped diamond anode. Water Air Soil Pollut 224:n1397

Bensalah N, Abdel-Wahab A (2013) Electrochemical inactivation of P. Aeruginosa, A. hydrophila, L. pneumophila using boron doped diamond anodes. J Adv Oxid Technol 16:9-15

Bheemaraddi MC, Patil S, Shivannavar CT, Gaddad SM (2014) Isolation and characterization of Paracoccus sp. GSM2 capable of degrading textile azo dye reactive violet 5. Sci World J 2014:410704. doi:10.1155/2014/410704

Brinzila CI, Pacheco MJ, Ciríaco L, Ciobanu RC, Lopes A (2012) Electrodegradation of tetracycline on BDD anode. Chem Eng J 209:54-61

Cañizares P, Sáez C, Sánchez-Carretero A, Rodrigo MA (2009) Synthesis of novel oxidants by electrochemical technology. J Appl Electrochem 39:2143-2149

Chung Y-C, Chen C-Y (2009) Degradation of azo dye reactive violet 5 by $\mathrm{TiO}_{2}$ photocatalysis. Environ Chem Lett 7:347-352

Deng Y, Ezyske CM (2011) Sulfate radical-advanced oxidation process (SR-AOP) for simultaneous removal of refractory organic contaminants and ammonia in landfill leachate. Water Res 45:6189-6194

Erler A, de Mas N, Ramsey P, Henderson G (2013) Efficient biological process characterization by definitive-screening designs: the formaldehyde treatment of a therapeutic protein as a case study. Biotechnol Lett 35:323-329

Fetyan NAH, Ali MMS, Break LM (2013) Biodegradation of a textile mono azo dye: Reactive Violet 5 by a novel isolated bacterial strain. Life Sci J 10:397-403

Georgiou SD, Stylianou S, Aggarwal M (2014) Efficient three-level screening designs using weighing matrices. Statistics 48:48815-48833

Griesbach U, Malkowsky IM, Waldvogel SR (2010) Green electroorganic synthesis using BDD electrodes. In: Comninellis C, Chen $G$ (eds) Electrochemistry for the environment. Springer, New York, pp 125-141

Hunger K (2003) Industrial dyes: chemistry, properties, applications. Wiley, Weinheim
Jain K, Shah V, Chapla D, Madamwar D (2012) Decolorization and degradation of azo dye-Reactive Violet $5 \mathrm{R}$ by an acclimatized indigenous bacterial mixed cultures-SB4 isolated from anthropogenic dye contaminated soil. J Hazard Mater 213-214:378-386

Jones B, Nachtsheim CJ (2011) A class of three-level designs for definitive screening in the presence of second-order effects. J Qual Technol 43:1-15

Khare UK, Bose P, Vankar PS (2007) Impact of ozonation on subsequent treatment of azo dye solutions. J Chem Technol Biotechnol 82:1012-1022

Libbrecht W, Deruyck F, Poelman H, Verberckmoes A, Thybaut J, De Clercq J, Van Der Voort P (2015) Optimization of soft templated mesoporous carbon synthesis using definitive screening design. Chem Eng J 259:126-134

Mascia M, Vacca A, Palmas S (2013) Electrochemical treatment as a pre-oxidative step for algae removal using Chlorella vulgaris as a model organism and BDD anodes. Chem Eng J 219:512-519

Michaud PA, Mahé E, Haenni W, Perret A, Comninellis Ch (2000) Preparation of peroxodisulfuric acid using boron-doped diamond thin film electrodes. Electrochem Solid State Lett 3:77-79

Montanaro D, Petrucci E (2009) Electrochemical treatment of Remazol Brilliant Blue on a boron-doped diamond electrode. Chem Eng J 153:138-144

Nandi BK, Patel S (2014) Removal of Brilliant Green from aqueous solution by electrocoagulation using aluminum electrodes: experimental, kinetics and modeling. Sep Sci Technol 49:601-612

Oturan N, Brillas E, Oturan MA (2012) Unprecedented total mineralization of atrazine and cyanuric acid by anodic oxidation and electro-Fenton with a boron-doped diamond anode. Environ Chem Lett 10:65-170

Perret A, Haenni W, Skinner N, Tang XM, Gandini D, Comninellis C, Correa B, Foti G (1999) Electrochemical behavior of synthetic diamond thin film electrodes. Diam Relat Mater 8:820-823

Petrucci E, Di Palma L, Lavecchia R, Zuorro A (2015a) Modeling and optimization of Reactive Green 19 oxidation on a BDD thin-film electrode. J Taiwan Inst Chem Eng 51:152-158

Petrucci E, Di Palma L, Lavecchia R, Zuorro A (2015b) Treatment of diazo dye Reactive Green 19 by anodic oxidation on a borondoped diamond electrode. J Ind Eng Chem 26:116-121

Scialdone O, Guarisco C, Galia A (2011) Oxidation of organics in water in microfluidic electrochemical reactors: theoretical model and experiments. Electrochim Acta 58:463-473

Sotgiu G, Foderà M, Marra F, Petrucci E (2014) Production and characterization of manganese oxide-based electrodes for anodic oxidation of organic compounds. Chem Eng Trans 41:115-120

Steter JR, Rocha RS, Dionísio D, Lanza MRV, Motheo AJ (2014) Electrochemical oxidation route of methyl paraben on a borondoped diamond anode. Electrochim Acta 117:127-133

Wang C, Chang S, Ye M, Ren Q (2013) Current efficiency and energy consumption of electrochemical oxidation for ammonia removal from coking wastewater using boron-doped diamond electrode. Appl Mech Mater 295-298:1327-1332

Xiao L, Lin DKJ, Bai F (2012) Constructing definitive screening designs using conference matrices. J Qual Technol 44:1-7

Zhou Y, Zhi J (2009) The application of boron-doped diamond electrodes in amperometric biosensors. Talanta 7:1189-1196

Zuorro A, Lavecchia R (2014) Evaluation of $\mathrm{UV} / \mathrm{H}_{2} \mathrm{O}_{2}$ advanced oxidation process (AOP) for the degradation of diazo dye Reactive Green 19 in aqueous solution. Desalin Water Treat 52:1571-1577

Zuorro A, Santarelli ML, Lavecchia R (2013) Tea waste: a new adsorbent for the removal of reactive dyes from textile wastewater. Adv Mater Res 803:26-29

Zuorro A, Petrucci E, Di Palma L, Lavecchia R (2014) Kinetic modelling of electrochemical decolorization of diazo dyes on boron-doped diamond electrodes. Chem Eng Trans 41:121-126 